\title{
The priming effect of extracellular UTP on human neutrophils: Role of calcium released from thapsigargin-sensitive intracellular stores
}

\author{
Florin Tuluc ${ }^{1}$, Ovidiu Bredetean ${ }^{1}$, Eugen Brailoiu ${ }^{2}$, John Meshki ${ }^{1}$, Analia Garcia ${ }^{1}$, Nae J. Dun ${ }^{2}$ \\ \& Satya P. Kunapuli ${ }^{1}$ \\ ${ }^{1}$ Department of Physiology, Temple University Medical School, Philadelphia, Pennsylvania, USA; \\ ${ }^{2}$ Department of Pharmacology, Temple University Medical School, Philadelphia, Pennsylvania, USA
}

Received 22 February 2005; accepted in revised form 3 June 2005

Key words: calcium, mitogen-activated protein kinases, neutrophil, P2Y receptors, reactive oxygen species

\begin{abstract}
$\mathrm{P}_{2} \mathrm{Y}_{2}$ receptors, which are equally responsive to ATP and UTP, can trigger intracellular signaling events, such as intracellular calcium mobilization and mitogen-activated protein (MAP) kinase phosphorylation in polymorphonuclear leukocytes (PMN). Moreover, extracellular nucleotides have been shown to prime chemoattractant-induced superoxide production. The aim of our study was to investigate the mechanism responsible for the priming effect of extracellular nucleotides on reactive oxygen species (ROS) production induced in human neutrophils by two different chemoattractants: formyl-methionyl-leucyl-phenylalanine (fMLP) and interleukin-8 (IL-8). Nucleotide-induced priming of ROS production was concentration- and time-dependent. When UTP was added to neutrophil suspensions prior to chemoattractant, the increase of the response reached the maximum at 1 min of pre-incubation with the nucleotide. UTP potentiated the phosphorylation of p44/42 and p38 MAP kinases induced by chemoattractants, however the P2 receptor-mediated potentiation of ROS production was still detectable in the presence of a SB203580 or U0126, supporting the view that MAP kinases do not play a major role in regulating the nucleotide-induced effect. In the presence of thapsigargin, an inhibitor of the ubiquitous sarco-endoplasmic reticulum $\mathrm{Ca}^{2+}$-ATPases in mammalian cells, the effect of fMLP was not affected, but UTP-induced priming was abolished, suggesting that the release of calcium from thapsigargin-sensitive intracellular stores is essential for nucleotide-induced priming in human neutrophils.
\end{abstract}

\section{Introduction}

Although ATP is abundantly present in living cells, it is mainly confined to the intracellular environment where it commonly reaches concentrations in low millimolar range [1]. ATP is found at even higher concentrations (approximately $150 \mathrm{mM}$ ) in chromaffin cells of the adrenal medulla [2]. There is strong evidence indicating that endothelial cells, activated platelets, sympathetic nerve endings as well as damaged cells can release significant amounts of ATP in the extracellular medium under a variety of pathological conditions such as atherosclerosis, hypertension, ischemia, and inflammation [1, 3]. UTP, although not as abundant as ATP, has been reported to be released from platelets, leukocytes, primary airway epithelial cells, rat astrocytes and several cell lines [4, 5]. Most mammalian cell types, including leukocytes, express on the plasma membrane receptors for extracellular nucleotides as well as ectonucleotidases, enzymes which are able to

Correspondence to: Dr Satya P. Kunapuli PhD, Department of Physiology, Temple University Medical School, 3420 N. Broad Street, OMS 224, Philadelphia, PA 19140, USA. Tel: +1-215-707-4615; Fax: +1-215-7074003; E-mail: spk@temple.edu quickly hydrolyze nucleotides [6]. It has been previously shown that ATP causes an enhancement of $N$-formylmethionyl-leucyl-phenylalanine (fMLP)-stimulated superoxide anion $\left(\mathrm{O}_{2}^{-}\right)$generation $[7,8]$ when added to human polymorphonuclear neutrophils at concentrations similar to those attained extracellularly at sites of platelet thrombus formation $(0.1$ to $20 \mu \mathrm{M})$. However, ATP by itself was unable to cause superoxide anion generation in isolated neutrophils [8]. Priming of the neutrophil respiratory burst has been implicated in the pathogenesis of multi-system organ failure after sepsis and trauma and appears to be mediated by multiple signaling pathways, depending on the particular priming agent and on the agonist [9]. MAP kinases have been shown to participate in the priming effect of TNF- $\alpha$ and granulocyte-macrophage colonystimulating factor (GM-CSF) but not in the case of platelet-activating factor (PAF) [9].

We have previously shown that the main nucleotide receptor mediating nucleotide-induced responses in neutrophils is the $\mathrm{P} 2 \mathrm{Y}_{2}$ receptor, which is equally responsive to ATP and UTP [10]. In the present study we performed a pharmacological characterization of the priming effect of nucleotides on ROS production induced by fMLP or IL-8. We also explored the effect of extracellular nucleotides on 
several intracellular signaling pathways involved in the potentiation effect of nucleotides. We found that although the phosphorylation of p44/42 (Erk) and p38 MAP kinases is enhanced by extracellular nucleotides, this event does not participate in priming. In addition, we investigated the role played by free cytosolic calcium in the priming effect of nucleotides. In isolated neutrophils, nucleotides cause increase of cytosolic free calcium by release from intracellular stores and through influx [11]. In calcium-depleted neutrophils fMLP-induced ROS production was significantly inhibited but the potentiating effect of nucleotides was still present, although not as robust as in cells maintained in medium containing physiological concentrations of calcium.

We showed for the first time that thapsigargin, a widely used inhibitor of the ubiquitous sarco-endoplasmic reticulum $\mathrm{Ca}^{2+}$-ATPases in mammalian cells, is able to selectively block the potentiating effect of nucleotides on fMLPinduced ROS production. Our data support the view that the release of calcium from thapsigargin-sensitive intracellular stores is essential for nucleotide-induced priming.

\section{Materials and methods}

Reagents. All nucleotides, SB203580 (4-(4-Fluorophenyl)2-(4-methylsulfinylphenyl)-5-(4-pyridyl)-1H-imidazole), U0126 (1,4-diamino-2,3-dicyano-1,4-bis(o-aminophenylmercapto) butadiene), brefeldin $\mathrm{A}$, thapsigargin, and bovine serum albumin (BSA; fraction V) were obtained from Sigma (St. Louis, Missouri, USA). Dextran T500, Ficoll-Paque were from Amersham Biosciences (Piscat- away, New Jersey, USA). CDP-Star with Nitro-Block II ${ }^{\circledR}$ from Tropix (Bedford, Massachusetts, USA) was used for chemiluminescent detection in Western blotting experiments. Fura-2 AM was from Molecular Probes (Eugene, Oregon, USA) and IL-8 was from Peprotech (Rocky Hill, New Jersey, USA). Polyclonal anti phospho-p44/42 MAP kinase (Thr202/Tyr204), anti-p44/442 MAP kinase, anti phospho-p38 MAP kinase (Thr180/Tyr182) antibodies, and anti p38 MAP kinase were from Cell Signaling Technology (Beverly, Massachusetts, USA).

Neutrophil isolation was performed as previously described [12]. Briefly, venous blood was collected upon written consent from healthy subjects in polypropylene tubes containing ACD anticoagulant (1.5\% citric acid, $2.5 \%$ sodium citrate, $2 \%$ dextrose). Blood was mixed with an equal volume of 3\% dextran T500 in saline. Erythrocytes were allowed to sediment for $20 \mathrm{~min}$ then leukocyte rich plasma was subjected to centrifugation on Ficoll-Paque at $400 \times g$ for $45 \mathrm{~min}$. The pellet was collected and the contaminating erythrocytes were removed by hypotonic lysis. Isolated neutrophils were resuspended in Hank's balanced salt solution (HBSS) containing $0.2 \%$ BSA. Neutrophils were counted using a Reichert-Jung hemacytometer (Hausser Scientific, Horsham, Pennsylvania, USA). Cell viability was checked by the Trypan blue exclusion method and was routinely found greater than $96 \%$.

Measurement of cytoplasmic free $\mathrm{Ca}^{2+}$ concentration. Isolated neutrophils were incubated for $45 \mathrm{~min}$ at room temperature in HBSS containing bovine serum albumin
A.

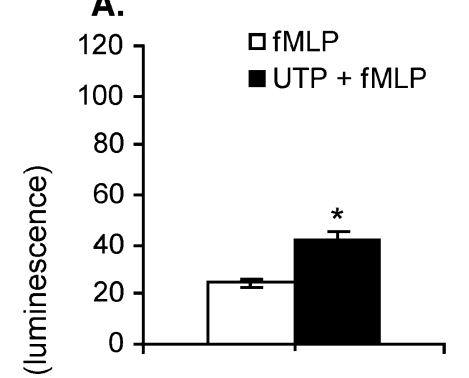

B.

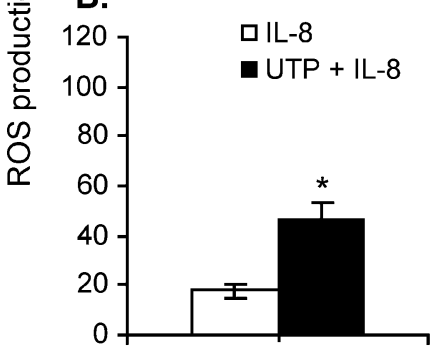

C.

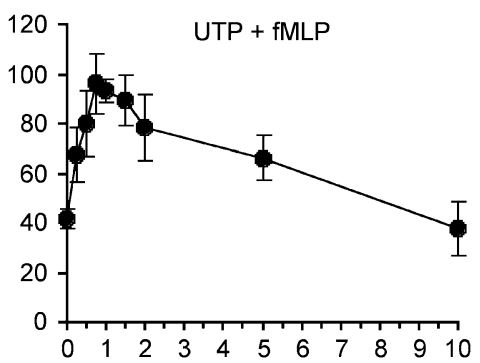

D.

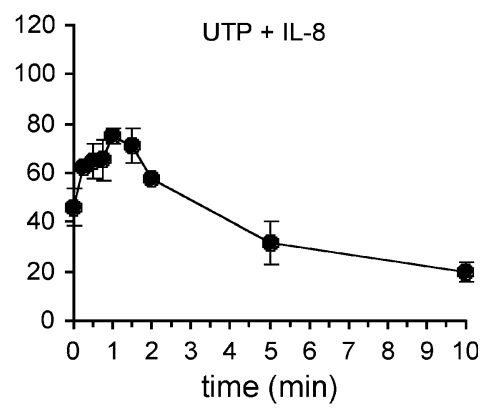

Figure 1. UTP potentiates AMP- or IL-8-induced ROS production in a time-dependent manner. Human neutrophils were isolated and ROS production was measured as described under Materials and methods. (A) and (B) The effect of f MLP (10 nM) or IL-8 (10 nM) was measured when administered alone (empty bars) or simultaneously with $10 \mu \mathrm{M}$ UTP (closed bars). (C) and (D) The effect of f MLP or IL-8 was measured when added at different intervals after the addition of UTP. Averages \pm SEM of peak luminescence signal measured in 4-6 experiments are shown. The luminescence peak measured upon the addition of a final concentration of $200 \mu \mathrm{M}$ of $\mathrm{H}_{2} \mathrm{O}_{2}$ to medium containing isoluminol (5 $\left.\mu \mathrm{M}\right)$ and horseradish peroxidase (1 U/ml) corresponds to $100 \mathrm{U}$ on the $Y$-axes. $(* P<0.05)$. 
$0.2 \%$ and $1 \mu \mathrm{M}$ Fura- $2 \mathrm{AM}$. The cells were washed twice and then resuspended at a concentration of $3 \times 10^{6} / \mathrm{ml}$ in HBSS containing BSA $0.2 \%$ and cytoplasmic free $\mathrm{Ca}^{2+}$ concentration was measured as previously described [12]. Briefly, aliquots of $0.5 \mathrm{ml}$ were placed in disposable methacrylate cuvettes under stirring conditions at $37^{\circ} \mathrm{C}$. Intracellular calcium concentrations were recorded during agonist stimulation using excitation wavelengths of 340 and $380 \mathrm{~nm}$ and the emission was monitored at $510 \mathrm{~nm}$ using an AB2 luminescence spectrophotometer (Spectronics Instruments, Rochester, New York, USA). Cytoplasmic concentrations of calcium were calculated according to Tsien's ratiometric method [13]. Averages of peak intracellular calcium concentrations were compared.

Measurement of ROS production. The release of ROS was measured as described elsewhere [14]. Briefly, horseradish peroxidase $(1 \mathrm{U} / \mathrm{ml})$ and isoluminol $(5 \mu \mathrm{M})$ were added to neutrophil suspensions $\left(2 \times 10^{6} / \mathrm{ml}\right)$ in a glass cuvette under stirring conditions, at $37{ }^{\circ} \mathrm{C}$ in a lumiaggregometer model 560-CA (Chronolog Corp., Havertown, Pennsylvania, USA). The cells were allowed to equilibrate for several minutes and reagents were added to the cell suspension while recording the luminescence signal on a chart recorder. For standardization purposes, hydrogen peroxide was used to assess the sensitivity of the peroxidase-isoluminol system and for normalization of data. The luminescence peak measured upon the addition of a final concentration of $200 \mu \mathrm{M}$ of $\mathrm{H}_{2} \mathrm{O}_{2}$ to medium containing isoluminol $(5 \mu \mathrm{M})$ and horseradish peroxidase $(1 \mathrm{U} / \mathrm{ml})$ was considered equal to $100 \mathrm{U}$. Averages of peak luminescence signals were compared.

Western blotting. Isolated human neutrophils $\left(6 \times 10^{6} / \mathrm{ml}\right)$ were incubated with UTP $(10 \mu \mathrm{M})$ or solvent for $1 \mathrm{~min}$ at $37{ }^{\circ} \mathrm{C}$ then cells were stimulated with $10 \mathrm{nM}$ fMLP or IL- 8 for $2 \mathrm{~min}$. The stimulation was terminated by adding to each sample an equal volume of $2 \times$ lysis buffer containing a mixture of protease and phosphatase inhibitors. The final concentrations of reagents in the lysis medium were: $25 \mathrm{mM}$ Tris- $\mathrm{HCl}, 150 \mathrm{mM} \mathrm{NaCl}, 5 \mathrm{mM}$ EDTA, $1 \%$ Triton X-100, $1 \mathrm{mM}$ PMSF, $10 \mu \mathrm{g} / \mathrm{ml}$ leupeptin, $10 \mu \mathrm{g} / \mathrm{ml}$ aprotinin, $1 \mathrm{mM}$ sodium vanadate, $2 \mathrm{mM}$ sodium pyrophosphate, $10 \mathrm{mM} \beta$-glycerol phosphate. The lysis was performed on ice for $20 \mathrm{~min}$ followed by centrifugation of the samples at $13,000 \mathrm{rpm}$ for $5 \mathrm{~min}$. A volume of 200 $\mu \mathrm{l}$ of the cytosolic fraction (the supernatant) was collected and mixed with $100 \mu \mathrm{l}$ of sample buffer containing: $6 \%$ sodium dodecyl sulphate, $30 \%$ glycerol, $3 \mathrm{mM}$ EDTA, $0.03 \%$ phenol red. Proteins were separated by SDSpolyacrylamide gel electrophoresis, transferred to ImmunBlot $^{\circledR}$ PVDF membrane (Bio-Rad, Hercules, California, USA) and incubated for $30 \mathrm{~min}$ in Tris buffered saline (TTBS; 20 mM Tris, 150 mM NaCl, 0.05\% Tween 20; pH 7.5) containing 2\% BSA (blocking buffer). Membranes were incubated overnight at $4{ }^{\circ} \mathrm{C}$ in the presence of the indicated primary antibody, which was diluted 1:1,000 in blocking buffer. Membranes were washed and incubated with appropriate secondary antibodies conjugated with alkaline phosphatase for $30 \mathrm{~min}$. Membranes were extensively washed and CDP-Star with Nitro-Block II ${ }^{\circledR}$ (Tropix, Bedford, Massachusetts, USA) was used for chemiluminescent detection of the reactive proteins on a Fujifilm LAS-1000 CCD system.

Data analysis. Statistical comparisons were made using one way analysis of variance (ANOVA). A $P$ value $<0.05$ was considered significant.

\section{Results}

Nucleotides potentiate ROS production induced by fMLP or IL-8 in a time- and dose-dependent manner

We performed a pharmacological characterization of the potentiating effect of extracellular nucleotides on the production of reactive oxygen species caused by two well-known chemoattractants, fMLP and IL-8. We tested ATP and UTP, two nucleotides that have been shown to be released in the extracellular medium under physiological or pathological conditions. When added alone to neutrophil suspensions, ATP and UTP did not cause measurable ROS production. However, both nucleotides were able to enhance the production of ROS induced by either IL-

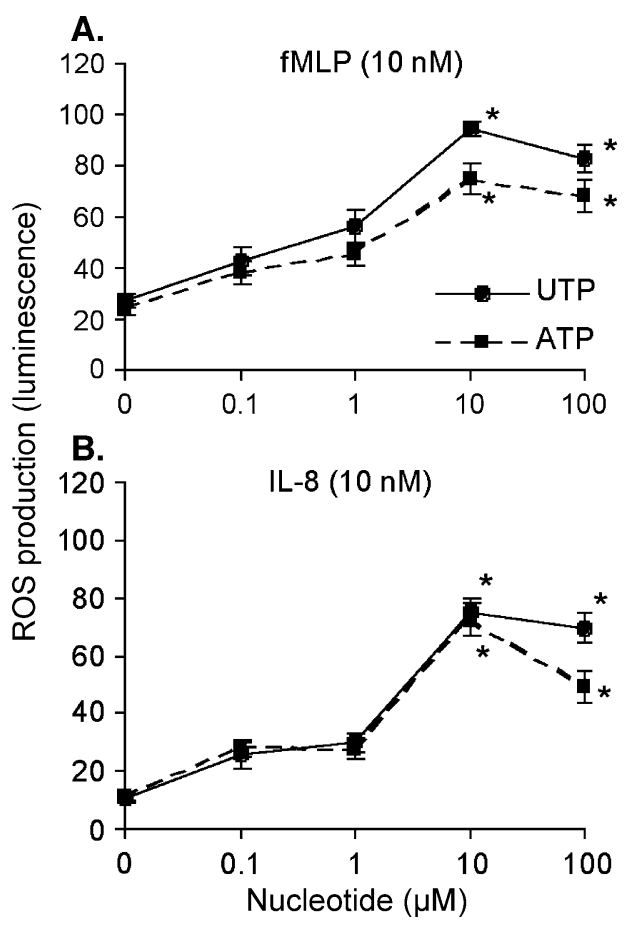

Figure 2. UTP and ATP potentiate fMLP- or IL-8-induced ROS production in a dose-dependent manner. Human neutrophils were isolated and ROS production was measured as described under Materials and methods. The effect of $10 \mathrm{nM}$ fMLP (A) or $10 \mathrm{nM} \mathrm{IL-8} \mathrm{(B)} \mathrm{was} \mathrm{measured}$ when administered alone or $1 \mathrm{~min}$ after the addition of increasing concentrations of UTP (circles) or ATP (squares). Averages \pm SEM of peak luminescence signal measured in 3-5 experiments are shown. The luminescence peak measured upon the addition of a final concentration of $200 \mu \mathrm{M}$ of $\mathrm{H}_{2} \mathrm{O}_{2}$ to medium containing isoluminol $(5 \mu \mathrm{M})$ and horseradish peroxidase $(1 \mathrm{U} / \mathrm{ml})$ corresponds to $100 \mathrm{U}$ on the $Y$-axes. $\left({ }^{*} P<0.05\right.$ when compared to the values measured in the absence of nucleotides.) 
A. Phospho-p44/42 MAPK

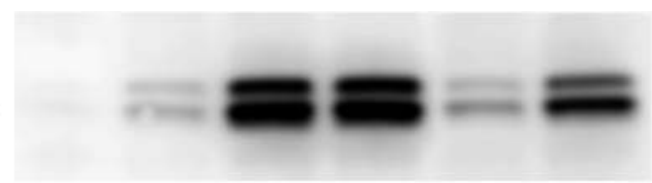

B. Phospho-p38 MAPK

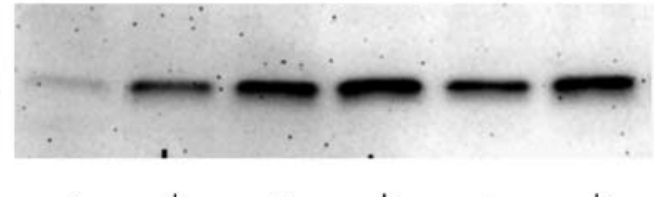
UTP $(10 \mathrm{mM})$ $\mathrm{fMLP}(10 \mathrm{nM})$ IL-8 (10 nM)

C.

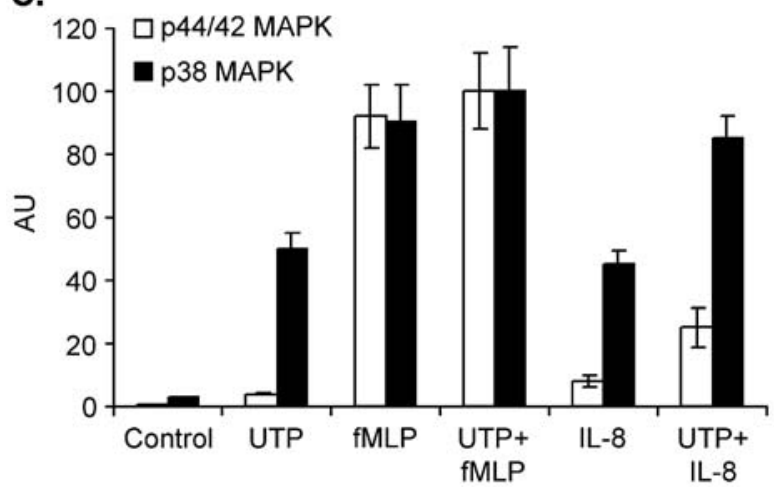

Figure 3. UTP induces MAP kinase phosphorylation. (A) and (B) Isolated human neutrophils ( 6 million/ml) were incubated with UTP (10 $\mu$ M) or solvent for $1 \mathrm{~min}$ at $37^{\circ} \mathrm{C}$ then cells were stimulated for $2 \mathrm{~min}$ with fMLP or IL-8, as indicated. Cells were lysed and solubilized proteins were separated by SDS-polyacrylamide gel electrophoresis. The detection of phosphorylated MAP kinases was performed as described under Materials and methods. (C) Densitometric analysis of images obtained from three Western blotting experiments. Data were normalized for the maximum effect obtained in cells stimulated with UTP and fMLP, which was considered equal to 100 arbitrary units (AU).

$8(10 \mathrm{nM})$ or fMLP $(10 \mathrm{nM})$. When a mixture of UTP and chemoattractant was added to neutrophil suspensions, a significant potentiation of the effect of chemoattractant was measured (Figures $1 \mathrm{~A}$ and $\mathrm{B}$ ). The potentiation of ROS production induced by IL-8 was higher (2.6-fold increase) as compared to the effect of fMLP (1.7-fold). In order to determine if the potentiation effect of nucleotides is timedependent, UTP $(10 \mu \mathrm{M})$ was added to neutrophil suspension at different intervals prior the addition of fMLP $(10 \mathrm{nM})$ or IL-8 $(10 \mathrm{nM})$. The maximal potentiating effect of UTP was detected when the addition of nucleotide was performed at $1 \mathrm{~min}$ before the addition of the chemoattractant (Figures 1C and D).

The relationship between the concentration of nucleotide and the priming effect was assessed by administering different concentrations of nucleotide at a fixed interval (1 min) before the addition of chemoattractant (Figure 2). The maximal effect of nucleotides was obtained at $10 \mu \mathrm{M}$, which is consistent with the potency described for these agonists at $\mathrm{P} 2 \mathrm{Y}_{2}$ receptors expressed in $1321 \mathrm{~N} 1$ cells, which are devoid of endogenous P2 receptors [15].

Nucleotides potentiate the phosphorylation of MAP kinases induced by $\mathrm{FMLP}$ and $I L-8$

MAP kinases have been reported to play a role in mediating neutrophil functions. In the present study we

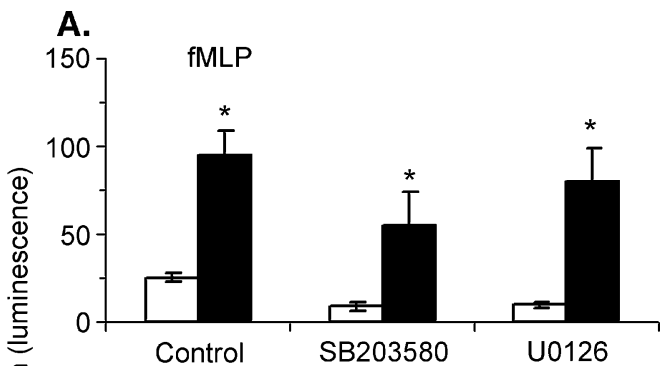

B.

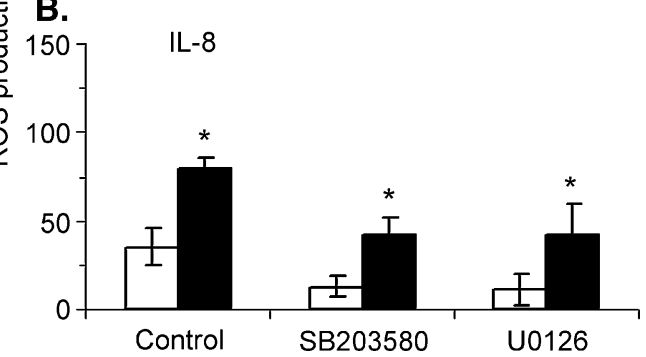

Figure 4. Inhibition of $\mathrm{p} 38$ or $\mathrm{p} 44 / 42$ MAP kinase has minor effect on the potentiating effect of nucleotides on ROS production. Isolated neutrophils were incubated with SB203580 $(10 \mu \mathrm{M})$ or U0126 $(3 \mu \mathrm{M})$ for $15 \mathrm{~min}$ then ROS production was measured as described under Materials and methods. The effect of f MLP $(10 \mathrm{nM})$ or IL-8 $(10 \mathrm{nM})$ was determined when administered $1 \mathrm{~min}$ after the addition of UTP $(10 \mu \mathrm{M}$; closed bars) or solvent (open bars). Averages \pm SEM of peak luminescence signal measured in $4-5$ experiments are shown $\left({ }^{*} P<0.05\right)$. 
Table 1. The effect of MAP kinase inhibitors on fMLP- or IL-8-induced ROS production in human neutrophils.

\begin{tabular}{lccc}
\hline & Control & $\mathrm{SB} 203580(10 \mu \mathrm{M})$ & $\mathrm{U} 0126(3 \mu \mathrm{M})$ \\
\hline Solvent + fMLP & $25.3 \pm 2.3$ & $8.5 \pm 2.5$ & $9.5 \pm 1.5$ \\
UTP + fMLP & $95.0 \pm 14.0$ & $54.6 \pm 19.7$ & $80.0 \pm 18.4$ \\
Fold increase & 3.8 & 6.4 & 8.4 \\
& & & \\
Solvent + IL-8 & $18.0 \pm 5.6$ & $6.4 \pm 2.8$ & $5.9 \pm 4.3$ \\
UTP + IL-8 & $79.0 \pm 7.0$ & $42.7 \pm 9.3$ & $42.4 \pm 17.4$ \\
Fold increase & 4.4 & 6.7 & 7.2 \\
\hline
\end{tabular}

ROS production was measured in isolated human neutrophils as described under Materials and methods. Cells were incubated with UTP $(10 \mu \mathrm{M})$ or solvent then fMLP $(10 \mathrm{nM})$ or IL-8 $(10 \mathrm{nM})$ were added to the medium. Averages \pm SEM of peak luminescence signal are presented. The luminescence peak measured upon the addition of a final concentration of $200 \mu \mathrm{M}$ of $\mathrm{H}_{2} \mathrm{O}_{2}$ to medium containing isoluminol $(5 \mu \mathrm{M})$ and horseradish peroxidase $(1 \mathrm{U} / \mathrm{ml})$ corresponds to $100 \mathrm{U}$. investigated the role of p44/42 and p38 MAP kinases in nucleotide-induced potentiation of ROS production. Both p44/42 and p38 MAP kinases have been shown to be activated by upstream kinases, which are able to phosphorylate specific residues. The p44/42 MAP kinase is activated by dual phosphorylation at Thr202 and Tyr204 [16], while p38 MAP kinase activation requires dual phosphorylation at Thr180 and Tyr182 [17]. We determined the phosphorylation of p44/42 and p38 MAP kinases by Western blotting, using phospho-specific antibodies.

UTP was able to weakly phosphorylate p44/42 MAP kinase and had a more prominent effect on the phosphorylation of p38 MAPK (Figure 3). We have previously shown that ATP had a similar effect on the phosphorylation of MAP kinases [10] consistent with the view that ATP and UTP act on a common receptor on human neutrophils. When added to neutrophils $60 \mathrm{~s}$ prior to the
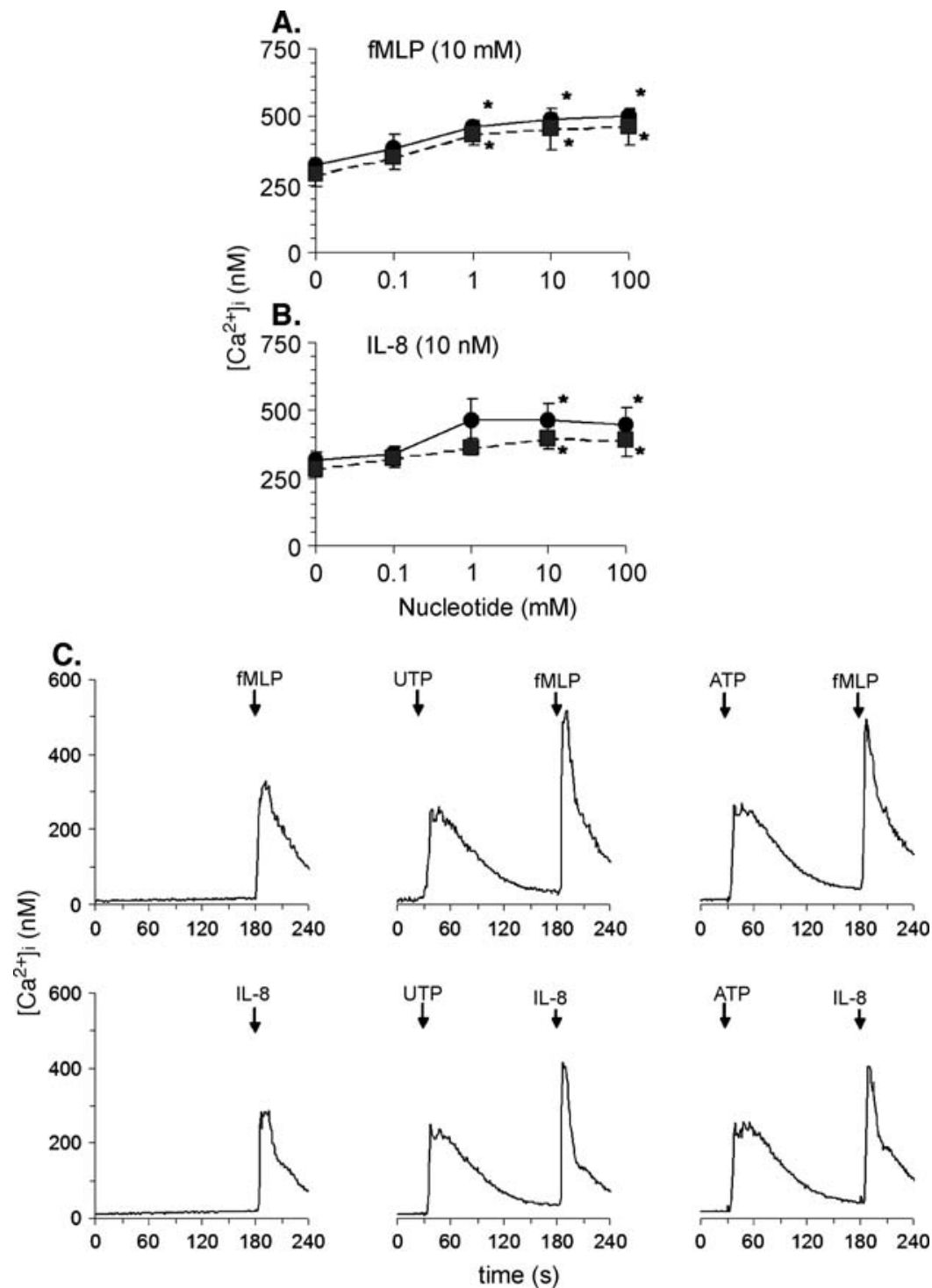

Figure 5. Nucleotides potentiate the increase of free cytosolic calcium triggered by fMLP or IL-8 in a dose-dependent manner. (A) and (B) Human neutrophils were isolated and intracellular calcium increase was measured as described under Materials and methods. The effect of fMLP (10 nM) or IL$8(10 \mathrm{nM})$ was measured when administered $2 \mathrm{~min}$ after the addition of different concentrations of UTP (circles) or ATP (squares). Averages \pm SEM of peak intracellular calcium concentrations measured in 4-5 experiments are shown. (C) Representative tracings obtained in neutrophils stimulated with chemoattractant alone (10 nM f MLP or $10 \mathrm{nM}$ IL-8) or with nucleotide (10 $\mu \mathrm{M}$ UTP or $10 \mu \mathrm{M}$ ATP) followed by chemoattractant. The reagents were added to cell suspensions where indicated on each individual tracing. 
stimulation with IL-8, UTP caused a marked increase of IL-8-induced phosphorylation of p44/42 kinase. Although UTP potentiated AMLP-induced MAP kinase phosphorylation and IL-8-induced phosphorylation of p38 MAP kinase, these effects were much less prominent.

\section{The potentiating effects of UTP on ROS production is not} affected by inhibition of MAP kinases

To determine whether or not MAP kinases play an essential role in the priming effect of nucleotides on superoxide production, we used SB203580 and U0126 as selective inhibitors of p38 and p44/42 MAP kinases, respectively. It has been previously shown that the pyridinyl imidazole SB203580 inhibits p38 kinase activity through competition with ATP and that its selectivity is probably determined by differences in nonconserved regions within or near the ATP binding pocket [18]. SB203580 is able to inhibit p38 MAP kinase activity in cells when used in concentrations up to $10 \mu \mathrm{M}$ [19]. U0126 is a potent inhibitor of MEK1/2, the enzymes responsible for the phosphorylation of $p 44 / 42$ MAP kinase [20]. We have determined that concentrations of U0126 as low as $3 \mu \mathrm{M}$ are able to completely inhibit the Erk phosphorylation induced by fMLP or by nucleotides in isolated human neutrophils (data not shown). Consistent with previous reports [21-24], we found that SB203580 has a modest but statistically significant inhibitory effect on fMLP-induced ROS production $(P<0.05$; Figure 4$)$. A similar effect was observed in the case of U0126. Although the levels of ROS measured in the presence of UTP were significantly lower in the presence of SB203580 or U0126, the potentiating effect of nucleotides was not inhibited by SB203580 (Table 1). In the case of IL-8, SB203580 or U0126 partially inhibited ROS production but they had no inhibitory effect on the potentiating effect of UTP.

Nucleotides potentiate intracellular calcium increase elicited by fMLP or IL-8. We and others [7, 10, 11, 25] have previously shown that extracellular nucleotides can cause intracellular calcium increase in isolated human neutrophils and this effect is partially resistant to the treatment with pertussis toxin. The intracellular calcium levels remain elevated for about $2 \mathrm{~min}$ before they return to baseline levels. A second addition of nucleotide causes no subsequent response due to receptor desensitization, which has been extensively described elsewhere [26, 27]. Although cross-desensitization between different receptors for chemoattractants has been described [28-30], nucleotides do not desensitize the responses to fMLP or IL-8 [28, 31]. Here we investigated the effect of the naturally occurring nucleotides ATP and UTP on the subsequent responses elicited by fMLP or IL-8. Neutrophils were stimulated with nucleotides and after $2 \mathrm{~min}$, when the concentration of cytosolic free calcium returned to values close to the resting levels, fMLP (10 nM) or IL-8 (10 $\mathrm{nM}$ ) were added to cell suspensions. We found that the responses to chemoattractants were enhanced by nucleotides in a dose-dependent manner, the maximum response being reached at $10 \mu \mathrm{M}$ (Figure 5). There were no significant differences between the effects caused by ATP and UTP.

Pretreatment of neutrophils for $20 \mathrm{~min}$ with $10 \mu \mathrm{M}$ brefeldin A, a widely used disrupter of calcium stores from Golgi apparatus [32] did not affect the potentiating effect induced by UTP on $\left[\mathrm{Ca}^{2+}\right]_{\mathrm{i}}$ peak.

\section{Thapsigargin prevents the potentiating effect of nucleotides on ROS production}

It is well established that the increase of cytosolic calcium in neutrophils relies both on mobilization from intracellular stores and on influx [11]. Nucleotides and chemoattractants are able to trigger both mechanisms hence we investigated the role of calcium originating from different sources on the potentiating effect of nucleotides on chemoattractantinduced ROS production.

When neutrophils are kept in calcium free medium for an extended period of time their responses to chemoattractants are markedly diminished due to depletion of intracellular stores of calcium [33]. However, when neutrophils were placed in calcium-free medium and fMLPinduced ROS production was immediately measured, we

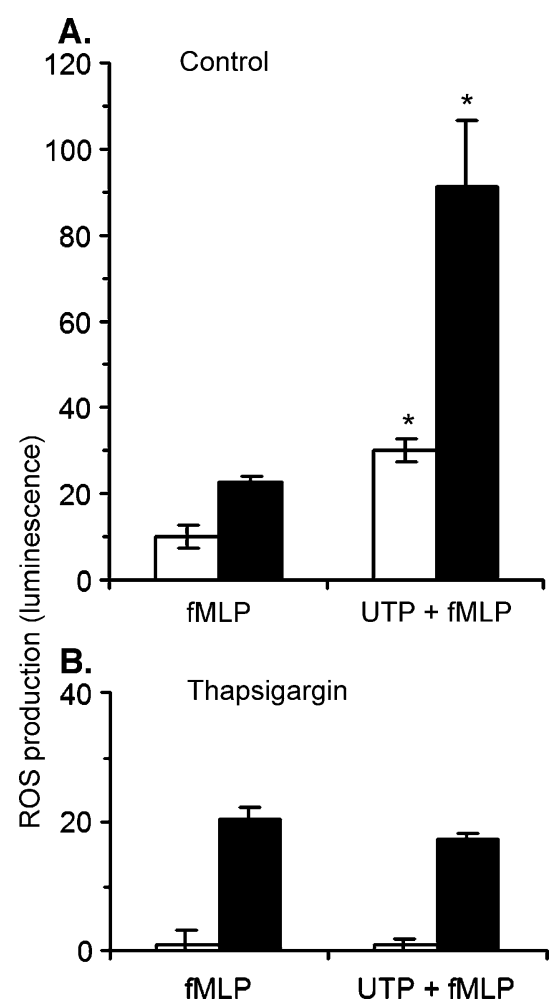

Figure 6. Thapsigargin selectively blocks the potentiating effect of UTP on $\mathrm{AMLP}$-induced ROS production. Isolated neutrophils were resuspended in medium containing $2 \mathrm{mM} \mathrm{CaCl}_{2}$ and $1 \mathrm{mM} \mathrm{MgCl}_{2}$ (closed bars) or in calcium and magnesium-free medium (empty bars). Cells were pre-treated for $20 \mathrm{~min}$ with solvent (A) or $100 \mathrm{nM}$ thapsigargin (B). UTP $(10 \mu \mathrm{m})$ or solvent was added to the medium followed after $1 \mathrm{~min}$ by fMLP (10 $\mathrm{nM})$. ROS production was determined as described under Materials and methods Averages \pm SEM of peak luminescence signal measured in 4-5 experiments are shown. The luminescence peak measured upon the addition of a final concentration of $200 \mu \mathrm{M}$ of $\mathrm{H}_{2} \mathrm{O}_{2}$ to medium containing isoluminol $(5 \mu \mathrm{M})$ and horseradish peroxidase $(1 \mathrm{U} / \mathrm{ml})$ corresponds to $100 \mathrm{U}$ on the $Y$-axes. $(* P<0.05)$. 
A.

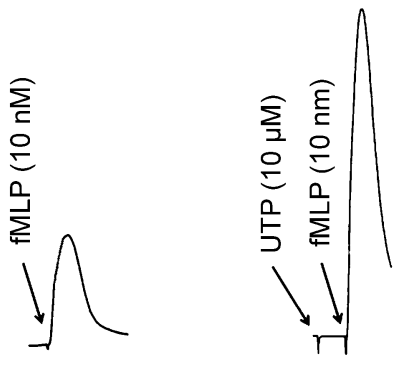

B.
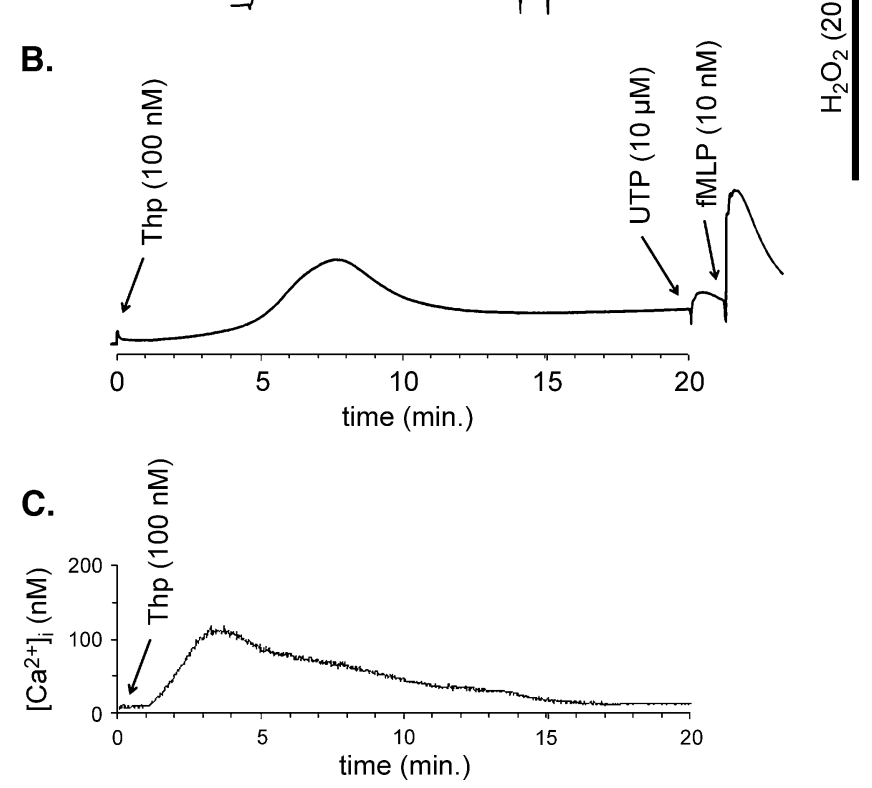

Figure 7. The effect of thapsigargin on the potentiating effect of UTP on fMLP-induced ROS production. Isolated neutrophils were incubated for 20 min with solvent (tracings in (A)) or $100 \mathrm{nM}$ thapsigargin (Thp tracing in (B)). UTP $(10 \mu \mathrm{M})$ and fMLP $(10 \mathrm{nM})$ were added as indicated in each panel. Vertical bar corresponds to the luminescence peak measured upon the addition of a final concentration of $200 \mu \mathrm{M} \mathrm{of} \mathrm{H}_{2} \mathrm{O}_{2}$ to medium containing isoluminol $(5 \mu \mathrm{M})$ and horseradish peroxidase $(1 \mathrm{U} / \mathrm{ml})$. Tracings are representative for data shown in Figure 6. (C) Thapsigargin $(100 \mathrm{nM})$ was added to fura-2 loaded neutrophils resuspended in calcium-free medium. Intracellular calcium concentration was recorded as described under Materials and methods.

found that the potentiating effect of UTP was reduced but still significant. When cells were incubated with thapsigargin $(100 \mathrm{nM})$ for $20 \mathrm{~min}$ in medium containing $2 \mathrm{mM}$ $\mathrm{CaCl}_{2}$, fMLP-induced ROS production was not affected, however the potentiating effect of UTP was completely abolished (Figures 6 and 7). Thapsigargin also inhibited the potentiating effect of UTP on IL-8 induced ROS production (data not shown). Thapsigargin caused a transient ROS production (Figure 7B) that may be due to activation of store-operated calcium entry. When cells were resuspended in calcium-free medium the addition of thapsigargin did not trigger ROS production and abolished fMLP-induced effect. A transient calcium increase was recorded when thapsigargin was added to neutrophils placed in calciumfree medium (Figure 7C). Pretreatment of neutrophils with brefeldin $\mathrm{A}(10 \mu \mathrm{M})$ failed to induce ROS production and did not affect the potentiating effect induced by UTP on ROS production (data not shown).

\section{Discussion}

In the present study we performed a pharmacological characterization of the priming effect of extracellular nucleotides on isolated human neutrophils. We determined that ATP and UTP can cause an immediate potentiating effect on ROS production, but the maximal effect elicited by nucleotides occurs after $1 \mathrm{~min}$ of exposure to nucleotide. This phenomenon may have physiological relevance since increased concentrations of nucleotides are expected to be present in the capillaries located closed to the inflammatory site. Nucleotides may function as a sensitizing factor, rendering the neutrophils the ability to respond to very low concentrations of chemoattractants. Thus, it is conceivable that nucleotides may prime the neutrophils in such a manner that they will be able to react at maximal levels when reaching the environment with elevated concentrations of chemoattractants.

We also determined that the potentiating effect of ATP and UTP is detectable at concentrations as low as $100 \mathrm{nM}$ and reaches a maximum at $10 \mu \mathrm{M}$, which is consistent with the concentration of ATP expected to be present in the extracellular environment of the inflammatory site.

Under physiological and pathological conditions the effect of ATP on human neutrophils is expected to be dependent on the activity of ectonucleotidases on most cells, these enzymes being able to quickly degrade the nucleotide triphosphates to nucleotide diphosphates, nucleotide monophosphates and finally to nucleosides [1, 34-36]. In some experiments ATP and UTP were used in 
parallel and they caused similar effects. For other experiments we chose to use UTP, since UTP is less likely to be degraded by ectonucleotidases. Thus, we avoided the biphasic effect that ATP has on neutrophils due to its degradation to adenosine, which has mainly inhibitory effects on this cell type [34]. Under our experimental conditions we observed that the potentiating effect of UTP tended to be higher as compared to the effect of ATP (Figure 2), probably due to the fact that UTP is less affected by enzymatic degradation.

Although high concentrations of ADP $(100 \mu \mathrm{M})$ caused a potentiating effect on fMLP-induced ROS production, this effect was most likely due to the contaminating ATP from commercially available nucleotides. Treatment of ADP with glucose $(22 \mathrm{mM})$ and hexokinase $(1 \mathrm{U} / \mathrm{ml})$ for 10 min in order to convert the contaminating ATP to ADP $[37,38]$ resulted in no potentiating effect of ADP (data not shown). AMP has also been reported as inactive at human neutrophils [39].

UTP is degraded by ectonucleotidases to UDP, UMP and uridine, and all these metabolites failed to affect the responses to chemoattractants (data not shown). Hence, while the stimulatory effect of ATP might be counterbalanced by adenosine, the effect of UTP may be longer lasting, since uridine is inactive. However, these hypotheses are not proven since the real concentrations of nucleotide, as well as the activity of ectonucleotidases at the inflammatory sites are difficult to quantify.

MAP kinases have been previously shown to be involved in ROS production; however, their involvement in nucleotide-mediated priming effect has not been tested. To determine if the activation of MAP kinases plays a role in the priming effect of nucleotides, we used SB203580, a p38 MAP kinase inhibitor, and U0126, an inhibitor of MEK1/2, the kinases responsible for the phosphorylation of $\mathrm{p} 44 / 42$. Since the P2 receptor-mediated potentiation of ROS production persisted in the presence of SB203580 or U0126, it appears that MAP kinases do not play a major role in the nucleotide-induced effect. Moreover, comparison of the ratio between the response elicited by chemoattractant alone and the response in the presence of UTP (Table 1) revealed no inhibitory effect of SB203580 or U0126 on UTP-induced potentiation. On the contrary, an increase of the potentiating effect of UTP was observed for both IL-8 and fMLP in the presence of MAP kinase inhibitors. A possible negative role of MAP kinases on the UTP-mediated potentiation of ROS production may explain the enhanced UTP-induced effect in the presence of MAP kinase inhibitors.

Stimulation of PMNs with IL-8 or fMLP results in increases in cytosolic calcium due to a combination of intracellular calcium release and influx of extracellular calcium. The first rapid increase in cytosolic calcium is due to PLC activation followed by $\mathrm{IP}_{3}$ generation and calcium release, mainly from endoplasmic reticulum. Subsequently, emptying of the intracellular calcium stores triggers a longer lasting influx of extracellular calcium through membrane channels (for a review see Niggli, 2003 [40]). PLC pathway has been demonstrated to have an important role in chemoattractant-mediated production of superoxide and regulation of certain protein kinases, but it has no major role in chemotaxis [41]. Recently, novel functionally active intracellular calcium stores have been identified in various cell types, the most important being Golgi apparatus and lysosomes [42] but the roles of these calcium sources in modulating cellular functions in neutrophils are still poorly defined.

We investigated the role of calcium in the potentiating effect of nucleotides. In neutrophils maintained for $30 \mathrm{~min}$ in calcium-free medium in order to deplete the intracellular stores, fMLP-triggered ROS production was inhibited and the UTP-induced potentiation was greatly inhibited. However, under such experimental conditions it is difficult to assess the degree of calcium depletion of intracellular stores.

Thapsigargin is the most widely used inhibitor of the ubiquitous sarco-endoplasmic reticulum $\mathrm{Ca}^{2+}$-ATPases in mammalian cells [43]. Its high potency and selectivity have been highly valuable in understanding the function of intracellular calcium stores in different processes. Following treatment with thapsigargin, neutrophils maintained in calcium-free medium failed to produce ROS upon stimulation with FMLP in the absence or presence of UTP. However, when physiological concentrations of calcium were present in the extracellular medium the fMLPmediated effect was restored, while no potentiating effect of UTP was detected. The fact that thapsigargin can block ROS production when neutrophils are placed in a calciumfree medium but not in the presence of extracellular calcium can be explained by the fact that NADPH oxidase activity in neutrophils require the presence of calcium. When extracellular calcium is present, thapsigargin triggers store operated calcium entry that supplies the necessary intracellular calcium. However, the potentiating effect of UTP is blocked in the presence of thapsigargin that causes depletion of calcium from endoplasmic reticulum. Our data strongly suggest that the mobilization of calcium from thapsigargin-sensitive stores is essential for the potentiating effect of UTP but it is not necessary for the fMLPinduced ROS production. It is well known that $\mathrm{IP}_{3}$ is able to release calcium from thapsigargin-sensitive calcium stores, related to the endoplasmic reticulum, as well as from thapsigargin-insensitive stores, such as Golgi calcium pool [44]. Since fMLP and UTP induce $\mathrm{IP}_{3}$ formation in human neutrophils [34], we next explored if disruption of Golgi calcium pool by brefeldin A [45] can alter the potentiating effect of UTP in a similar manner as thapsigargin. Alteration of Golgi calcium stores had no effect on UTP-induced potentiation of fMLP effect on ROS production, suggesting that $\mathrm{IP}_{3}$-sensitive Golgi calcium pool is not involved in this process.

We conclude that calcium release from thapsigarginsensitive but not from Golgi intracellular stores is essential for the priming effect of nucleotides. This mechanism of controlling ROS production in neutrophils can be viewed as a potential target for drugs that may be useful to treat pathological conditions associated with excessive neutrophil activation [46], such as ischemia-reperfusion and burn injuries, arthritis and allergic reactions. 


\section{Acknowledgement}

This work was supported by a Research Grant HL63933 from the National Institutes of Health.

\section{References}

1. Lazarowski ER, Boucher RC, Harden, TK. Mechanisms of release of nucleotides and integration of their action as P2X- and P2Y-receptor activating molecules. Mol Pharmacol 2003; 64: 785-95.

2. Bankston LA, Guidotti G. Characterization of ATP transport into chromaffin granule ghosts. Synergy of ATP and serotonin accumulation in chromaffin granule ghosts. J Biol Chem 1996; 271: 17132-8.

3. Burnstock G. Purinergic signaling and vascular cell proliferation and death. Arterioscler Thromb Vasc Biol 2002; 22: 364-73.

4. Lazarowski ER, Harden TK. Quantitation of extracellular UTP using a sensitive enzymatic assay. Br J Pharmacol 1999; 127: 1272-8.

5. Eltzschig HK, Ibla JC, Furuta GT et al. Coordinated adenine nucleotide phosphohydrolysis and nucleoside signaling in posthypoxic endothelium: Role of ectonucleotidases and adenosine $\mathrm{A} 2 \mathrm{~B}$ receptors. J Exp Med 2003; 198: 783-96.

6. Beukers MW, Pirovano IM, van Weert A et al. Characterization of ecto-ATPase on human blood cells. A physiological role in platelet aggregation? Biochem Pharmacol 1993; 46: 1959-66.

7. Kuhns DB, Wright DG, Nath $\mathrm{J}$ et al. ATP induces transient elevations of $\left[\mathrm{Ca}^{2+}\right]_{\mathrm{i}}$ in human neutrophils and primes these cells for enhanced $\mathrm{O}_{2}{ }^{-}$generation. Lab Invest 1988; 58: 448-53.

8. Seifert R, Wenzel K, Eckstein F, Schultz G. Purine and pyrimidine nucleotides potentiate activation of NADPH oxidase and degranulation by chemotactic peptides and induce aggregation of human neutrophils via G proteins. Eur J Biochem 1989; 181: 277-85.

9. Yaffe $\mathrm{MB}, \mathrm{Xu} \mathrm{J}$, Burke PA et al. Priming of the neutrophil respiratory burst is species-dependent and involves MAP kinase activation. Surgery 1999; 126: 248-54.

10. Meshki J, Tuluc F, Bredetean $\mathrm{O}$ et al. Molecular mechanism of nucleotide-induced primary granule release in human neutrophils: Role for the $\mathrm{P}_{2} \mathrm{Y}_{2}$ receptor. Am J Physiol Cell Physiol 2004; 286: C264-71.

11. Walker BA, Hagenlocker BE, Douglas VK et al. Nucleotide responses of human neutrophils. Lab Invest 1991; 64: 105-12.

12. Tuluc F, Meshki J, Kunapuli SP. Membrane lipid microdomains differentially regulate intracellular signaling events in human neutrophils. Int Immunopharmacol 2003; 3: 1775-90.

13. Grynkiewicz G, Poenie M, Tsien RY. A new generation of $\mathrm{Ca}^{2+}$ indicators with greatly improved fluorescence properties. J Biol Chem 1985; 260: 3440-50.

14. Granfeldt D, Dahlgren C. An intact cytoskeleton is required for prolonged respiratory burst activity during neutrophil phagocytosis. Inflammation 2001; 25: 165-9.

15. Janssens R, Paindavoine P, Parmentier M, Boeynaems JM. Human P2Y2 receptor polymorphism: Identification and pharmacological characterization of two allelic variants. Br J Pharmacol 1999; 127: 709-16.

16. Payne DM, Rossomando AJ, Martino P et al. Identification of the regulatory phosphorylation sites in $\mathrm{pp} 42 /$ mitogen-activated protein kinase (MAP kinase). EMBO J 1991; 10: 885-92.

17. Raingeaud J, Gupta S, Rogers JS et al. Pro-inflammatory cytokines and environmental stress cause p38 mitogen-activated protein kinase activation by dual phosphorylation on tyrosine and threonine. J Biol Chem 1995; 270: 7420-6.

18. Young PR, McLaughlin MM, Kumar S et al. Pyridinyl imidazole inhibitors of p38 mitogen-activated protein kinase bind in the ATP site. J Biol Chem 1997; 272: 12116-21.

19. Clerk A, Sugden PH. The p38-MAPK inhibitor, SB203580, inhibits cardiac stress-activated protein kinases/c-Jun N-terminal kinases (SAPKs/JNKs). FEBS Lett 1998; 426: 93-6.
20. Favata MF, Horiuchi KY, Manos EJ et al. Identification of a novel inhibitor of mitogen-activated protein kinase kinase. J Biol Chem 1998; 273: 18623-32.

21. Coxon PY, Rane MJ, Uriarte $\mathrm{S}$ et al. MAPK-activated protein kinase-2 participates in p38 MAPK-dependent and ERK-dependent functions in human neutrophils. Cell Signal 2003; 15: 993-1001.

22. Kim C, Dinauer MC. Rac2 is an essential regulator of neutrophil nicotinamide adenine dinucleotide phosphate oxidase activation in response to specific signaling pathways. J Immunol 2001; 166: 1223-32.

23. Lal AS, Clifton AD, Rouse $\mathrm{J}$ et al. Activation of the neutrophil NADPH oxidase is inhibited by SB 203580, a specific inhibitor of SAPK2/p38. Biochem Biophys Res Commun 1999; 259: 465-70.

24. $\mathrm{Zu} \mathrm{YL,} \mathrm{Qi} \mathrm{J,} \mathrm{Gilchrist} \mathrm{A} \mathrm{et} \mathrm{al.} \mathrm{p38} \mathrm{mitogen-activated} \mathrm{protein} \mathrm{kinase}$ activation is required for human neutrophil function triggered by TNF-alpha or FMLP stimulation. J Immunol 1998; 160: 1982-9.

25. Seifert R, Burde R, Schultz G. Activation of NADPH oxidase by purine and pyrimidine nucleotides involves $\mathrm{G}$ proteins and is potentiated by chemotactic peptides. Biochem J 1989; 259: 813-9.

26. Garrad RC, Otero MA, Erb L et al. Structural basis of agonistinduced desensitization and sequestration of the P2Y2 nucleotide receptor. Consequences of truncation of the $\mathrm{C}$ terminus. J Biol Chem 1998; 273: 29437-44.

27. Otero M, Garrad RC, Velazquez B et al. Mechanisms of agonistdependent and -independent desensitization of a recombinant P2Y2 nucleotide receptor. Mol Cell Biochem 2000; 205: 115-23.

28. Tomhave ED, Richardson RM, Didsbury JR et al. Cross-desensitization of receptors for peptide chemoattractants. Characterization of a new form of leukocyte regulation. J Immunol 1994; 153: 3267-75.

29. Didsbury JR, Uhing RJ, Tomhave E et al. Receptor class desensitization of leukocyte chemoattractant receptors. Proc Natl Acad Sci USA 1991; 88: 11564-8.

30. Richardson RM, Ali H, Tomhave ED et al. Cross-desensitization of chemoattractant receptors occurs at multiple levels. Evidence for a role for inhibition of phospholipase C activity. J Biol Chem 1995; 270: 27829-33.

31. Ali H, Richardson RM, Haribabu B, Snyderman R. Chemoattractant receptor cross-desensitization. J Biol Chem 1999; 274: 6027-30.

32. Kok JW, Babia T, Filipeanu CM et al. PDMP blocks brefeldin A-induced retrograde membrane transport from golgi to ER: Evidence for involvement of calcium homeostasis and dissociation from sphingolipid metabolism. J Cell Biol 1998; 142: 25-38.

33. Geiszt M, Szeberenyi JB, Kaldi K, Ligeti E. Role of different Ca2+ sources in the superoxide production of human neutrophil granulocytes. Free Radic Biol Med 1999; 26: 1092-9.

34. Zhang Y, Palmblad J, Fredholm BB. Biphasic effect of ATP on neutrophil functions mediated by $\mathrm{P} 2 \mathrm{U}$ and adenosine A2A receptors. Biochem Pharmacol 1996; 51: 957-65.

35. Sneddon P, Westfall TD, Todorov LD et al. Modulation of purinergic neurotransmission. Prog Brain Res 1999; 120: 11-20.

36. Birk AV, Broekman MJ, Gladek EM et al. Role of extracellular ATP metabolism in regulation of platelet reactivity. J Lab Clin Med 2002; 140: $166-75$.

37. Nicholas RA, Lazarowski ER, Watt WC et al. Pharmacological and second messenger signalling selectivities of cloned P2Y receptors. J Auton Pharmacol 1996; 16: 319-23.

38. Nicholas RA, Watt WC, Lazarowski ER et al. Uridine nucleotide selectivity of three phospholipase C-activating P2 receptors: Identification of a UDP-selective, a UTP-selective, and an ATP- and UTPspecific receptor. Mol Pharmacol 1996; 50: 224-9.

39. Fredholm BB. Purines and neutrophil leukocytes. Gen Pharmacol 1997; 28: 345-50.

40. Niggli V. Signaling to migration in neutrophils: Importance of localized pathways. Int J Biochem Cell Biol 2003; 35: 1619-38.

41. Li Z, Jiang $\mathrm{H}$, Xie $\mathrm{W}$ et al. Roles of PLC- $\beta 2$ and $-\beta 3$ and $\mathrm{PI} 3 \mathrm{Kgamma}$ in chemoattractant-mediated signal transduction. Science 2000; 287: 1046-9.

42. Brailoiu E, Patel S, Dun NJ. Modulation of spontaneous transmitter release from the frog neuromuscular junction by interacting intracellular $\mathrm{Ca}^{2+}$ stores: Critical role for nicotinic acid- 
adenine dinucleotide phosphate (NAADP). Biochem J 2003; 373: 313-8.

43. Treiman M, Caspersen C, Christensen SB. A tool coming of age Thapsigargin as an inhibitor of sarco-endoplasmic reticulum $\mathrm{Ca}(2+)$ ATPases. Trends Pharmacol Sci 1998; 19: 131-5.

44. Pinton P, Pozzan T, Rizzuto R. The Golgi apparatus is an inositol 1,4,5-trisphosphate-sensitive $\mathrm{Ca}^{2+}$ store, with functional properties distinct from those of the endoplasmic reticulum. Embo J 1998; 17: 5298-308.

45. Filipeanu CM, Brailoiu E, Costuleanu $M$ et al. Vasorelaxant properties of brefeldin A in rat aorta. Eur J Pharmacol 1997; 332: $71-6$.

46. Mathison RD, Befus AD, Davison JS, Woodman RC. Modulation of neutrophil function by the tripeptide feG. BMC Immunol 2003; 4: 3 . 